\title{
Review - New Media Caucus Showcase A perspective on consciousness within digital practices
}

\author{
DEBORA FACCION \\ Artist, PhD Candidate Binghamton University
}

\section{Presentations by the following NMC members:}

- Sophia Brueckner, Assistant Professor, University of Michigan

- Martin Calvino, Artist-in-residence at Rutgers University

- Zach Duer, Assistant Professor, Creative Technologies, Virginia Tech

- Carter Eggleston, MFA candidate in Creative Technologies, Virginia Tech

- Elizabeth Flyntz, Artist, Writer, and curator

- Jeffrey Gangwisch, strikeWare co-founder and Adjunct Professor, Anne Arundel Community College

- Chelsea Heikes, candidate at European Graduate School

- Laura Hyunjhee Kim, Ph.D. candidate, University of Colorado Boulder

- George Legrady, Distinguished Professor of Interactive Media and director of Experimental Visualization Lab, UC Santa Barbara

- Maya Livio, Ph.D Candidate, University of Colorado Boulder, Curator of Media Archaeology Lab, Curator of MediaLive at BMoCA

- Eric Souther, Associate Professor of New Media, Indiana University South Bend

- Deirtra Thompson, Independent artist, practitioner, and researcher

- Masha Vlasova, Lecturer and Lead Faculty, University of North Texas

- Michelle Hernandez, MFA alumna, Hunter College, CUNY

- Dominika Ksel, Adjunct Assistant Professor of New Media, Baruch College, CUNY.

An annual tradition at the College Arts Association conference, the New Media Caucus Showcase brings together artists working with new media, electronic and digital art. Now in its tenth year, the Showcase highlights the work of New Media Caucus members who are selected by lottery to give seven-minute presentations. The absence of curatorial effort in the selection of artists creates the possibility of bringing together a diverse group of people working with a range of practices, from visual art generated from the manipulation of DNA sequences to audiovisual installation, digital video and sculpture, to virtual avatars and bodily transformations. Perhaps the most interesting result of the lottery, however, isn't so much the diversity of practices, but the identification of current trends among different artists working in the field of new media. For instance, several artists in the Showcase explore questions regarding human consciousness, perception, and experience in the digital age. These artists, instead of employing digital tools to transform traditional forms of art, are questioning the consequences of the use of digital technologies on the experiences of being ourselves and being with others. The result is the 
creation of artworks that question the digital in itself, that is, works that speak not only to how we use the digital, but how we become tools for the digital to generate itself.

Opening the showcase, Sophia Brueckner presented a project that looks at the most popular highlighted sentences in romance novels on Kindle. Brueckner argues that the highlighting tool on Kindle enables the formation of groups of people who share interests and who interact anonymously through highlighting passages, which Brueckner defines as an "unintentional social network." To highlight a popular passage in a book means to join a small digital community that bonds through only a few words, which, nevertheless, is enough to transform the individuality of the act of reading into a social act. Brueckner prints the popular passages that carry multiple highlights on illustrated porcelain memorable plates, which become mementos of the participation in such communities (Figure 1). The porcelain plates can be seen both as a visual intervention into the act of reading and as the materialization of one of the experiences that we participate in while cultivating our digital existence. While highlighting a passage in a book is a mundane action, to highlight a passage in tandem with others produces a network of social activity. Brueckner's porcelain plates become then, an expression of the power of the digital to build itself by registering and accumulating actions that were previously done in isolation.

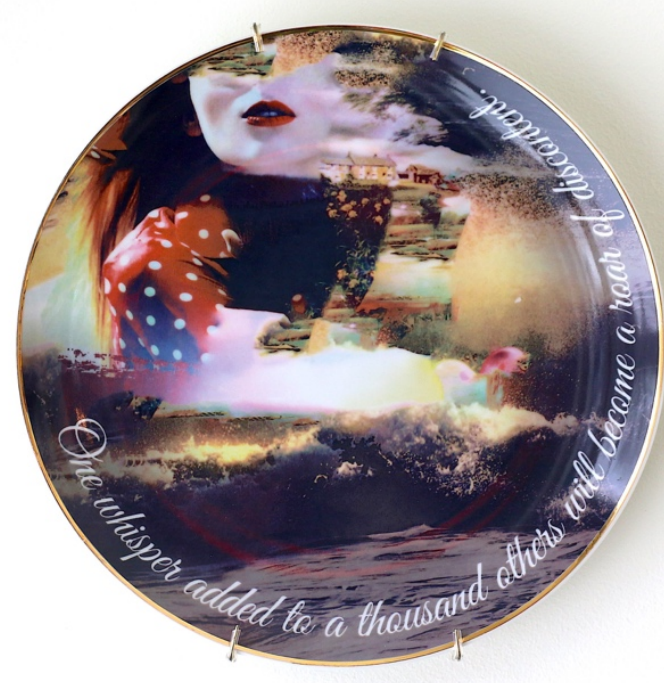

Figure 1 One whisper added to a thousand others will become a roar of discontent." Image from Sophia Brueckner's presentation. http://www.sophiabrueckner.com/romance.html

Similarly playing with the relationship between digital expression and material objects, Margaret Dolinsky develops an art practice that speaks openly about the artist's experiences with developing her own consciousness of the human body. Right after waking up in the morning, Dolinsky begins by intuitively drawing on paper to recreate the imagery of her dreaming state. 
She then animates these drawings with digital tools (Figure 2). The resulting images are used to illustrate virtual environments, generate sculptures, and even stage operas. Dolinksy's practice reveals the experiential possibilities opened by digital images, by expanding the exchange between reality and imagination.

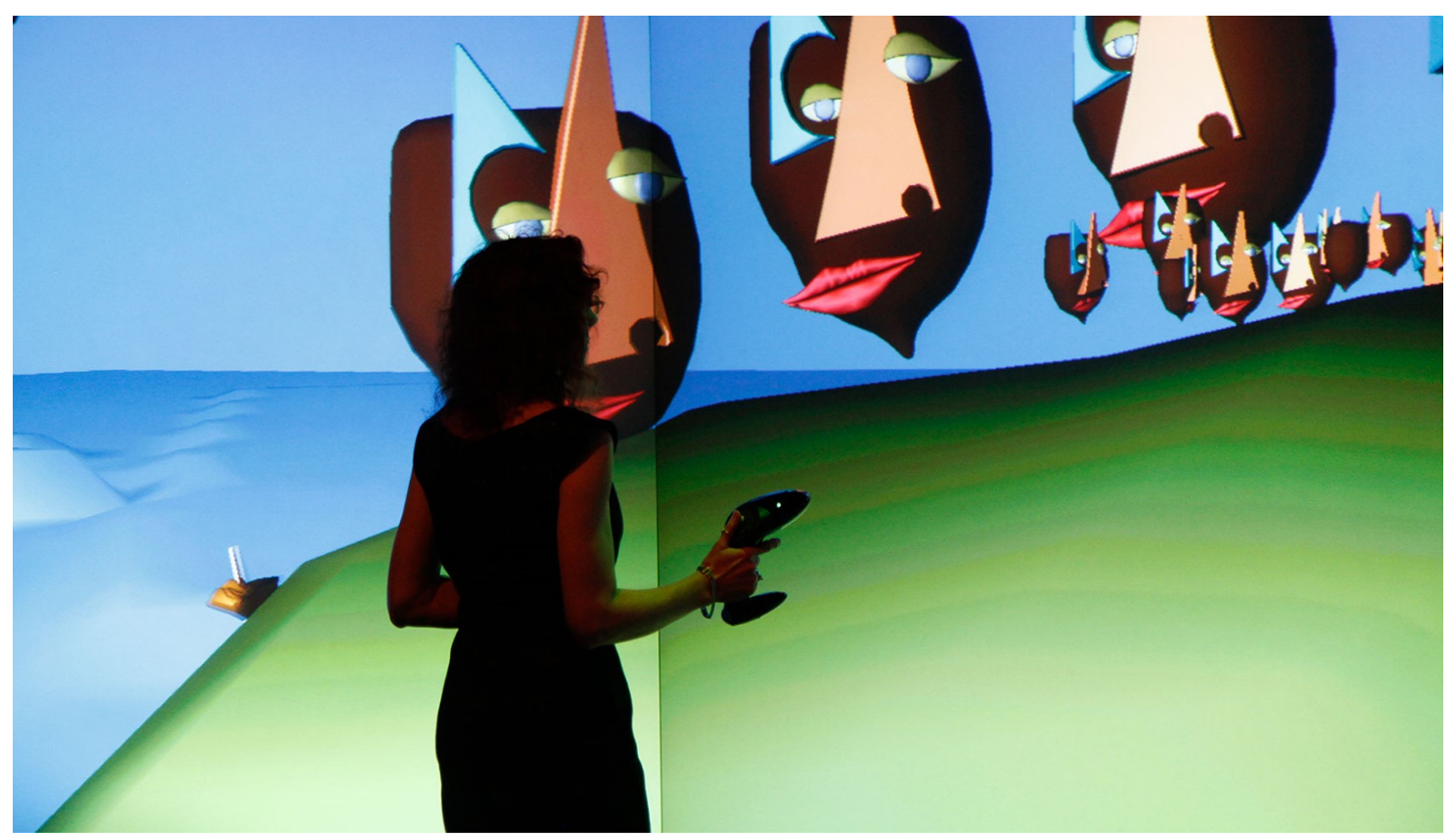

Figure 2 A virtual environment with Margaret Dolinsky's digital drawings. Image from Dolinsky's presentation. https://soaad.indiana.edu/about/faculty/dolinsky-margaret.html

Michelle Hernandez Vega, in contrast, starts her making process with the creation of a repertoire of images that brings the understanding of the digital in direct relation to the movements and making capacities of human hands (Figure 3). Insisting that, "the emotional connection to digital technology happens mostly because we touch the devices. Our phones are like hand puppets," Vega brings attention to the unwavering connection that we establish between our bodies and digital tools. Her work disrupts the divide between bodily materiality and virtual reality, placing her within a new generation of artists who have been using these technologies since their childhood (Figure 4). In this way, Vega's work becomes a way to explore her Puerto Rican heritage and to process personal and collective traumas. In 2017, Vega returned to Puerto Rico after Hurricane Maria and witnessed the collapse of electronic and communication systems in its aftermath. This experience is reflected in Vega's digital videos, which blur the lines that divide our consciousness between digital and material worlds, bringing to attention the interrelation between material experiences and the existence of the digital. 


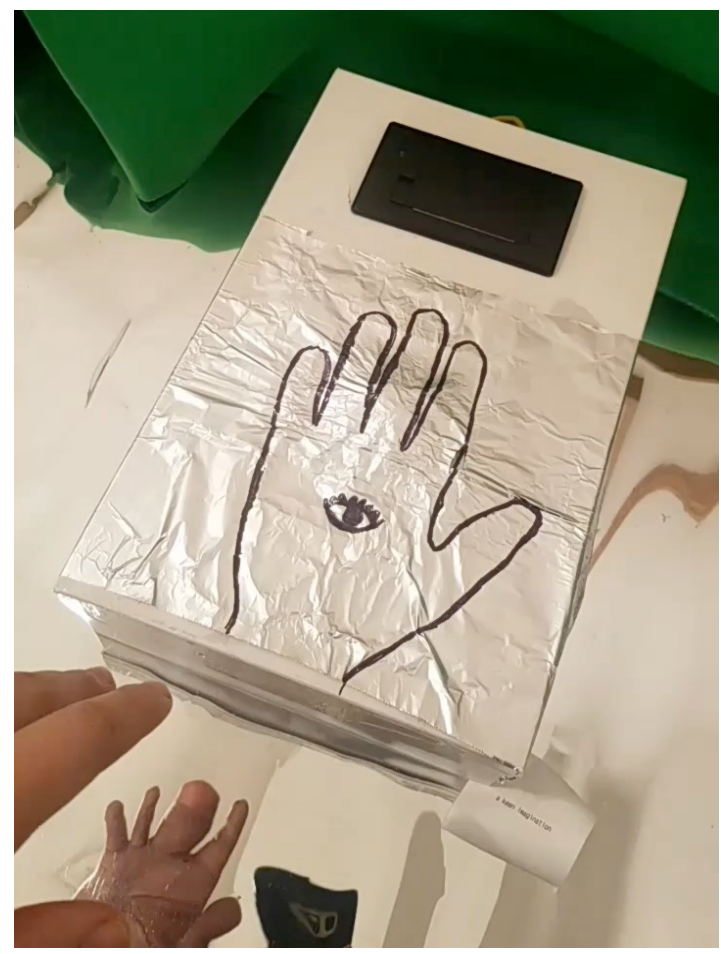

Figure 3 Image of a previous work that commented on the power of human hands. Image from Michelle Hernandez Vega's presentation. http://www.michellehernandezvega.com/

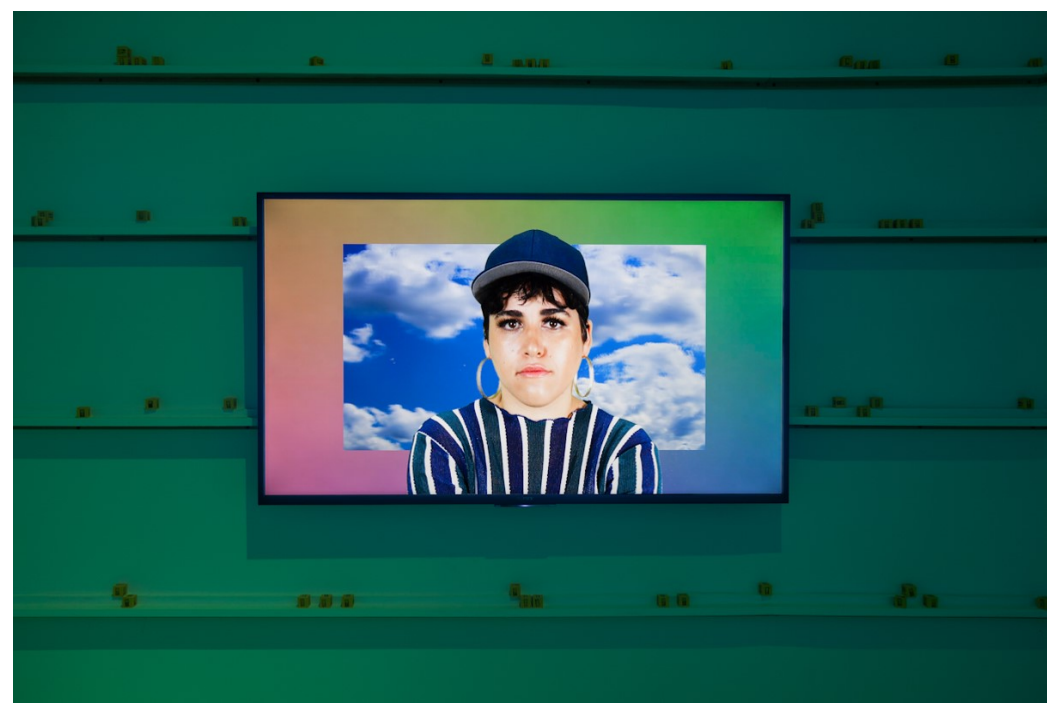

Figure 4 An image of the artist in one of her digital videos. Image from Michelle Hernandez Vega's presentation.

Laura Hyunjhee Kim's work, on the other hand, explores the totalizing capacity of the digital to encompass our experiences. Kim creates an entire corporation with multiple employees in a website that collects her performances as different tech-specialist workers, holding invented positions like "Speculative Human Research Lab" and "Human and Nonhuman Resources Manager" along with common positions like "Chief Engineer" and "Public Relations Director" 
(Figure 5). Kim's project, SEICA, encompasses this corporate website, itself a kind of performance, containing detailed texts for each of the characters and a complete and recognizably business-like structure, with typical organization into sections like "About," "Press," and "Contact." The website shows the possibility within the digital world to create fictional narratives that fit familiar formats for distributing information. Moreover, SEICA shows the possibility, within the digital, to create human and non-human personalities, giving agency and existence to fictive characters. Overall, the project builds the artist's digital identity, questioning the boundaries that we establish between others and ourselves through the creation of professional titles and through our presence in virtual environments.
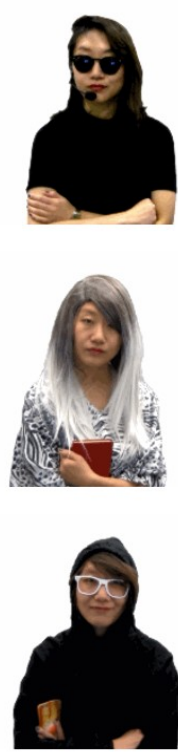
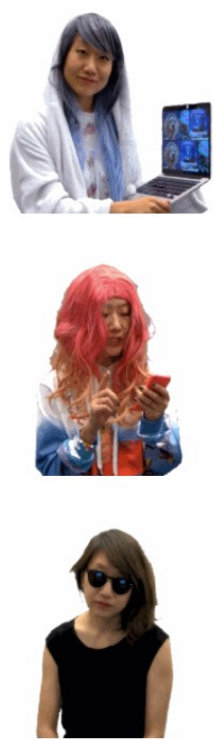
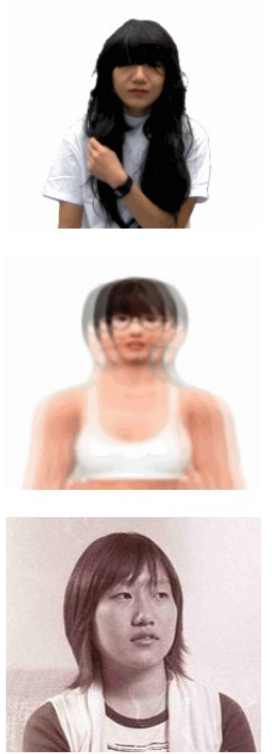
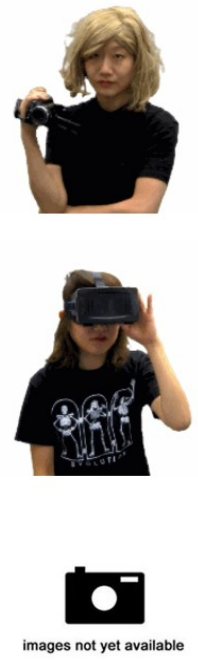
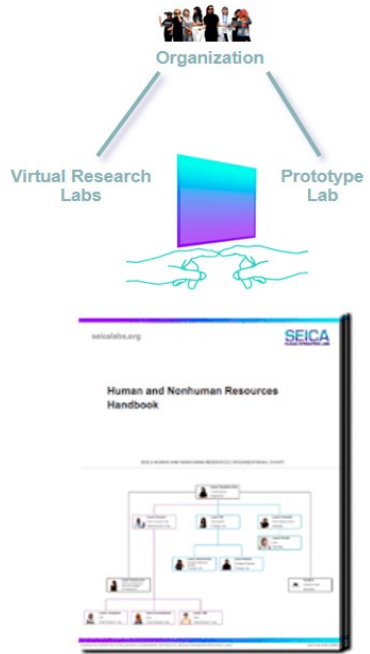

Figure 5 The various performances of the artist in SEICA. Image from Laura Hyunjhee Kim's presentation. http://www.lauraonsale.com/seica.html

Marsha Vlasova uses digital imagery to question one particular socially established boundary, that of the visual specificities that define male and female bodies and determine expressions of desire. Vlasova created a short documentary, Her Type, in which her mother uses a phone app to give "male features" to a picture of the artist's face (Figure 6). The result of this image manipulation is that Vlasova's picture is reminiscent of how her father looked when he met her mother, who, in the video, is impressed and moved by the image. Vlasova concludes "The image creates an opportunity for my mother to express her desire for me via the image of me as my father, while my camera frames my mother's image, fetishizing it." (Figure 7) However, Vlasova's conclusion disregards the fact that the image that her mother sees is neither her nor her father, but a digital creation of an imaginary body. Vlasova's perception of her own work assigns to digital images powers of persuasion that can reshape our experiences with others, even in intimate relationships like those between mother and daughter. 


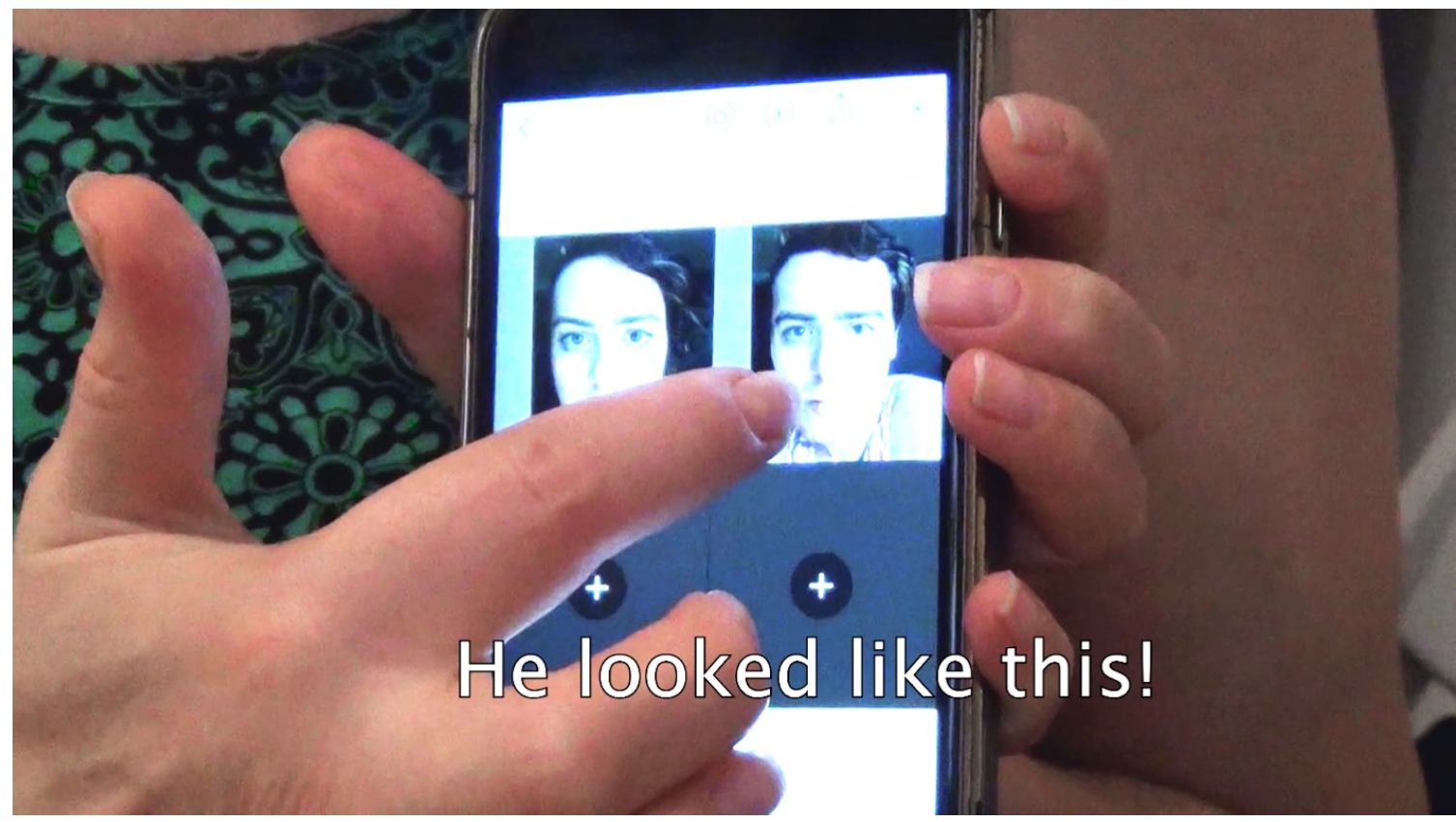

Figure 6 Still from Marsha Vlasova's video “Her type”. Image from Marsha Vlasova's presentation. https://art.unt.edu/people/masha-vlasova

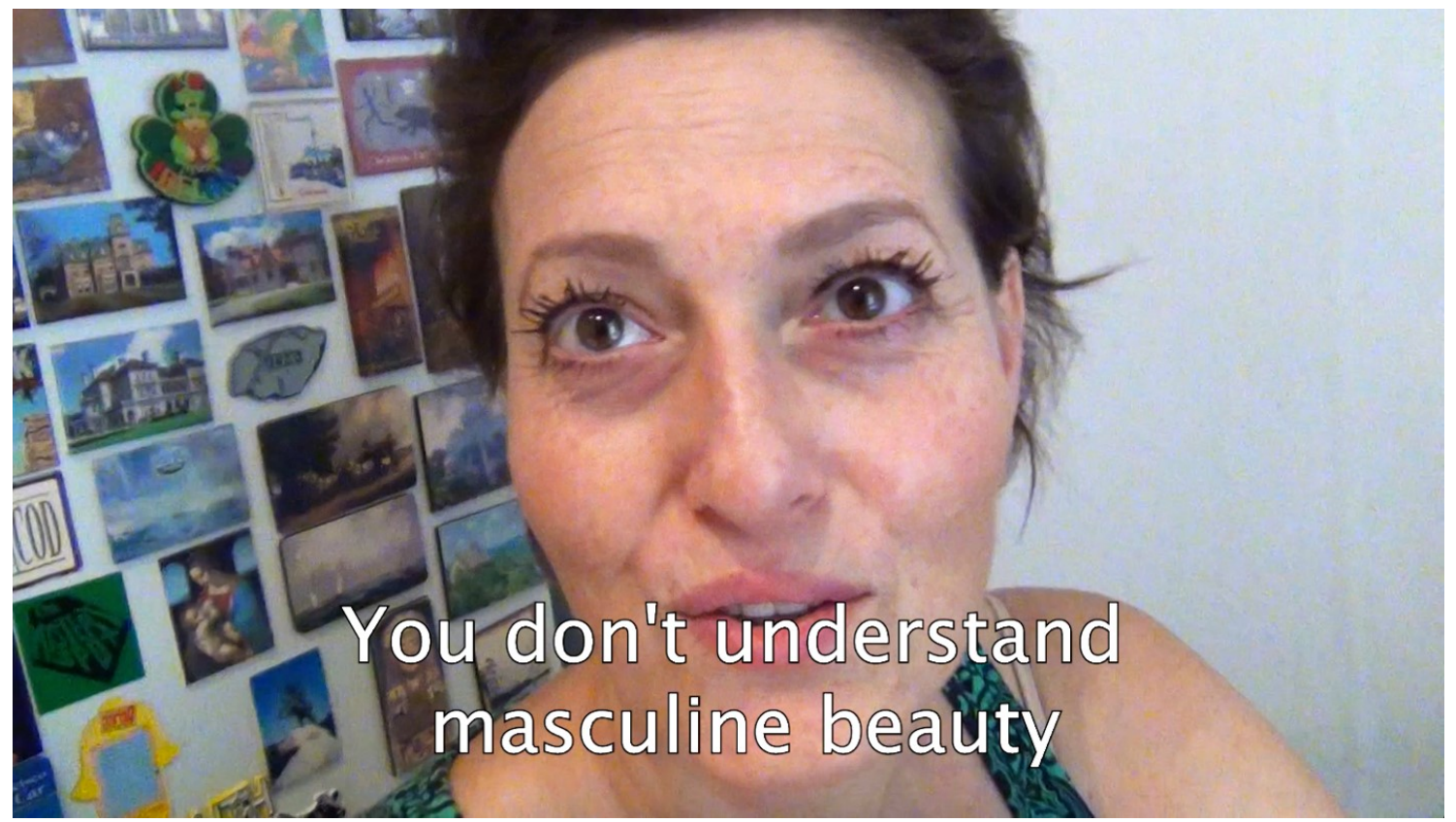

Figure 7 Still from Marsha Vlasova's video “Her type”. Image from Marsha Vlasova's presentation. 
To conclude, the New Media Caucus Showcase provides an opportunity to recognize common themes and strategies among a wide range of new media art practices. For instance, one could explore the use of high technology for the creation of interactive images, like in the works of George Legrady, Zach Duer and Carter Eggleson. Alternatively, projects presented by Deirtra Thompson and Liz Flyntz question environmental and psychological standards, showing the developments of digital technologies and propositions for new or critical perspectives on the markets that benefit from these standards. The works that I selected from the Showcase in this review, on the other hand, deal with the consequences of the use of the digital as a form of thinking, that is, as a distinct way of articulating experiences that can impact and transform our consciousness.

\section{AUTHOR BIO}

Debora Faccion is a visual artist from Brazil and a PhD candidate in Art History at SUNY Binghamton. Her work deals with the translation of concepts and values between cultures, as well as the constraints and possibilities of different media used by artists. In her dissertation, she focuses on the work by Brazilian artist Antonio Dias, within the social and political context of the 1970s. Currently, she is an Adjunct Lecturer in the Art \& Design department at Binghamton University, teaching a course on "Critical Theory and Creativity" in the BFA program and a Graduate Fellow in the Material and Visual Worlds Transdisciplinary Area of Excellence at Binghamton University. http://www.dharmalibertas.com 